\title{
Financial Markets- Investment Strategy through Predictive and Statistical Analysis using Big Data and MATLAB
}

\author{
Vishal Kannan ${ }^{1}$ \\ Student, Mechanical Engineering, RV College of Engineering, Bengaluru, India ${ }^{1}$
}

\begin{abstract}
Predicting public company stock upswing and downswing is a very complex and mathematical problem. Accurate prediction of public stock performances can be beneficial to hedge funds, private investors as well as the common public interested in investment in stock.The biotechnology industry has grown rapidly in recent years, doubling in size between 1993 and 1999. 150,800 of the US jobs were generated directly by biotechnology companies, while the remaining 286,600 jobs were generated by companies supplying inputs to the industry, or by companies providing goods and services to biotechnology employees. Biotechnology is a field of science which has enormous potential in growing into a global crisis savior with recent developments ranging from easy surgical techniques and cheap pharmaceuticals to solutions in carcinogenic problems and nanotechnology. Due to the presence of solutions to such immensely concerning humanitarian problems, Biotechnology would soon serve as a backbone to human sustenance and evolution. All this would only mean that the stock prices of such a sector would boom to great heights in the near future. Due to this reason, in depth analysis of stocks of public Biotechnology companies is very important. In this paper, an elegant real-time public stock performance prediction methodology based on an aggregation of historical stock performances and organizational stock properties using a set of top US Biotechnology public companies has been introduced. In this paper, a striking co relation between the stock price and market capitalization swings of the companies with the number of employees has been reported. With these temporal stock swings, repeater operator analysis has been used to establish a statistical veracity of the novel metric of these top biotech companies. This corresponds to a result of profit, $85 \%$ of the time. A MATLAB model has also been developed to aid automate the stock performance prediction methodology reported in this. This method lends itself to broaden a large scale statistical validation as well as development of more advanced and complex models for stock performance prediction. For this analysis, exactly 9,234 data points were considered by manual data mining.
\end{abstract}

Keywords: Earnings per share, P/E Ratio, Shares Outstanding, Market Capitalization, Innovation Potential (IP).

\section{INTRODUCTION}

Stock markets were always a very intriguing study for me because of its lack of predictability and its ability to baffle an entire country and its global economy. In 2014, China's economy crashed and left an entire nation awestruck. China's total bank debt has grown from $\$ 14$ trillion in 2008 to $\$ 25$ trillion today - more than double the total size of the US commercial banking sector. This was a major concern for the big-time investors and hedge funds as they lost massive amounts of money. This was the motivating factor in this paper. In this paper, a new methodology is introduced to improve the predictive power of stock market prediction. On $19^{\text {th }}$ September 2014, Hilary Clinton released a statement of a social medial website about a fight against the price of pharmaceutical prescription products. This led to a sudden drop in stock price which shook the confidence of even fearless investors. Such debates that arise in the biotechnology stock market causes a lot of liquidity in the stock which attracted me to study more on this and start research on Big data analysis of Biotechnology stock.

Big data analytics is the process of collecting, organizing and analysing large sets of data to discover patterns and other useful information. Big data analytics can help organizations to better understand the information contained within the data and will also help identify the data that is most important to the business and future business decisions. Analysts working with big data basically want the knowledge that comes from analysing the data. As the technology that helps an organization to break down data silos and analyse data improves, business can be transformed in all sorts of ways. The biggest challenge of big data analysis is the sheer volume of the data itself. To maximize the capability of this and reduce cumbersomeness, learning of software such as MATLAB which as tremendous compiling power is essential. Enterprises are increasingly looking to find actionable insights into their data. Many big data projects originate from the need to answer specific business questions. With the right big data analytics platforms in place, an enterprise can boost sales, increase efficiency, and improve operations, customer service and risk management. 
There are two prices that are critical for any investor to know: the current price of the investment he or she owns, or plans to own, and its future selling price. Most investors have a certain behaviour of staying of stocks which have risen sharply recently with the assumption have the "shoot" is over. Investors also avoid on stocks that have been dropping consistently assuming a technical problem inside the company leading to the poor performance of the company. There are generally three types of investors, namely full time investors (aim for small frequent profits), weekly and monthly investors (view stock fluctuation every week) and long term investors (aim to get large profits over a course of a few years generally also partner with the company to provide funds).

\section{DISADVANTAGES OF CURRENT PREDICTION METRICS}

\section{A. Earnings per share}

Earnings per share is the ratio of profit in a particular time period and current share price. If earnings per share is high, the profit is high and share price is low. But this is based on past performance and does not tell us about future potential. It merely tells us whether a company did well in chosen time frame or not.

\section{B. P/E Ratio}

$\mathrm{P} / \mathrm{E}$ ratio is the ratio of market price of share and the earnings per share. If $\mathrm{P} / \mathrm{E}$ ratio is high, it implies that the market price is high. It could also mean that the market price is high compared to the earnings per share. Hence it put the investor in a dilemma whether to invest or not and puts the pressure back on the investor.

\section{III.PROPOSED METHODOLOGY}

\section{A. Definitions and terms}

\section{- $\quad$ Shares Outstanding}

Shares outstanding refers to all shares currently owned by stockholders, company officials, and investors in the public domain, but does not include shares repurchased by a company.

\section{- $\quad$ Market Capitalization}

Market Capitalization is the product of number of shares outstanding and the current share price. This gives the investor a general idea of the worth of the company.

\section{- $\quad$ Initial Public Offering}

An initial public offering (IPO) is the first sale of stock by a private company to the public. IPOs are often issued by smaller, younger companies seeking the capital to expand, but can also be done by large privately owned companies looking to become publicly traded.

\section{- $\quad$ Share Price}

B. The Method

- $\quad$ The proposed method of stock prediction is illustrated using the following steps-

1. The historical shares outstanding and the stock prices of the companies were recorded.

2. The total number of employees at the time of investment were recorded.

3. Using historical shares outstanding and share price, the historical market capital was calculated.

4. A self-generated metric know as innovation potential was calculated (Innovation potential is the ratio of market capital in hundred thousand and the current number of employees.

5. A hypothesis was made that the companies with a higher innovation potential are most likely to grow in the next three months. (It is expected that the investor holds the invested stock for the time period of three months)

6. Receiver Operator analysis was used to test the correctness is the proposed idea.

7. Thresholding of the companies were done as "innovative", "non-innovative" and others.

8. The proposed innovative companies were indeed innovative with a chance of profit $85 \%$ of the times.

\section{- What an investor must do}

1. Input a spreadsheet with historical shares outstanding, share price and number of employees.

2. Feed this input into the MATLAB code.

3. Observe the Innovation Potential (IP) values.

4. Invest in the stocks that have a high IP values according to the provided thresholds. 




Data points example of Innovative Companies 


\begin{tabular}{|c|c|c|}
\hline$\Delta$ & A & $\mathrm{P}$ \\
\hline 1 & & Chimerix Inc \\
\hline 2 & Stock Symbol & CMRX \\
\hline 3 & Founded & 2002 \\
\hline 4 & Went Public on (CrunchBase) & 2013 \\
\hline 5 & Minimum Private Investment in Million (CrunchBase) & 256.4 \\
\hline 6 & Headquarters & $\mathrm{NC}$ \\
\hline 7 & Medical keywords & Antivirals \\
\hline 8 & Number of Employees (MorningStar) & \\
\hline 9 & Date - Number of Employees (MorningStar) & \\
\hline 10 & Number of Full Time Emloyees (MorningStar) & \\
\hline 11 & NUMBER OF EMPLOYEES (Bloomberg) & 104 \\
\hline 12 & Num of Employees (Linkedin) & 111 \\
\hline 13 & VALUATION PER EMPLOYEE(in 100K USD per Employee) & 221.15 \\
\hline 14 & VALUATION PER EMPLOYEE (in 100K - MorningStar) & \\
\hline 15 & Valuation/employee according to Linkedin & 207.21 \\
\hline 16 & Shares Outstanding JUNE 14(END,MIL) & 35.4 \\
\hline 17 & Shares Outstanding JULY 14 & 35.53 \\
\hline 18 & Shares Outstanding AUGUST 14 & 35.67 \\
\hline 19 & Shares Outstanding SEPTEMBER 14 & 36.41 \\
\hline 20 & Shares Outstanding OCTOBER 14 & 36.44 \\
\hline 21 & Shares Outstanding NOVEMBER 14 & 36.48 \\
\hline 22 & Shares Outstanding DECEMBER 14 & 41.03 \\
\hline 23 & Shares Outstanding JANUARY 15 & 42.06 \\
\hline 24 & Shares Outstanding FEBRUARY 15 & 41.09 \\
\hline 25 & Shares Outstanding MARCH 15 & 41.31 \\
\hline 26 & Shares Outstanding APRIL 15 & 41.32 \\
\hline 27 & Shares Outstanding MAY 15 & 43.58 \\
\hline 28 & Shares Outstanding JUNE 15 & 45.85 \\
\hline 29 & Shares Outstanding JULY 15 & 46.07 \\
\hline 30 & Share Price JUNE 14 & 21.94 \\
\hline 31 & Share Price JULY 14 & 22.72 \\
\hline 32 & Share Price AUGUST 14 & 22.71 \\
\hline 33 & Share Price SEPTEMBER 14 & 27.62 \\
\hline 34 & Share Price OCTOBER 14 & 31.04 \\
\hline 35 & Share Price NOVEMBER 14 & 31.41 \\
\hline 36 & Share Price DECEMBER 14 & 40.26 \\
\hline 37 & Share Price JANUARY 15 & 41.78 \\
\hline 38 & Share Price FEBRUARY 15 & 41.41 \\
\hline 39 & Share Price MARCH 15 & 37.69 \\
\hline 40 & Share Price APRIL 15 & 37.53 \\
\hline 41 & Share Price MAY 15 & 41.85 \\
\hline 42 & Share Price JUNE 15 & 46.2 \\
\hline 43 & Share Price JULY 15 & 53.74 \\
\hline 44 & Market Capital JUNE 14(MIL) & 776.676 \\
\hline 45 & Market Capital JULY 14 & 807.2416 \\
\hline 46 & Market Capital AUGUST 14 & 810.0657 \\
\hline
\end{tabular}




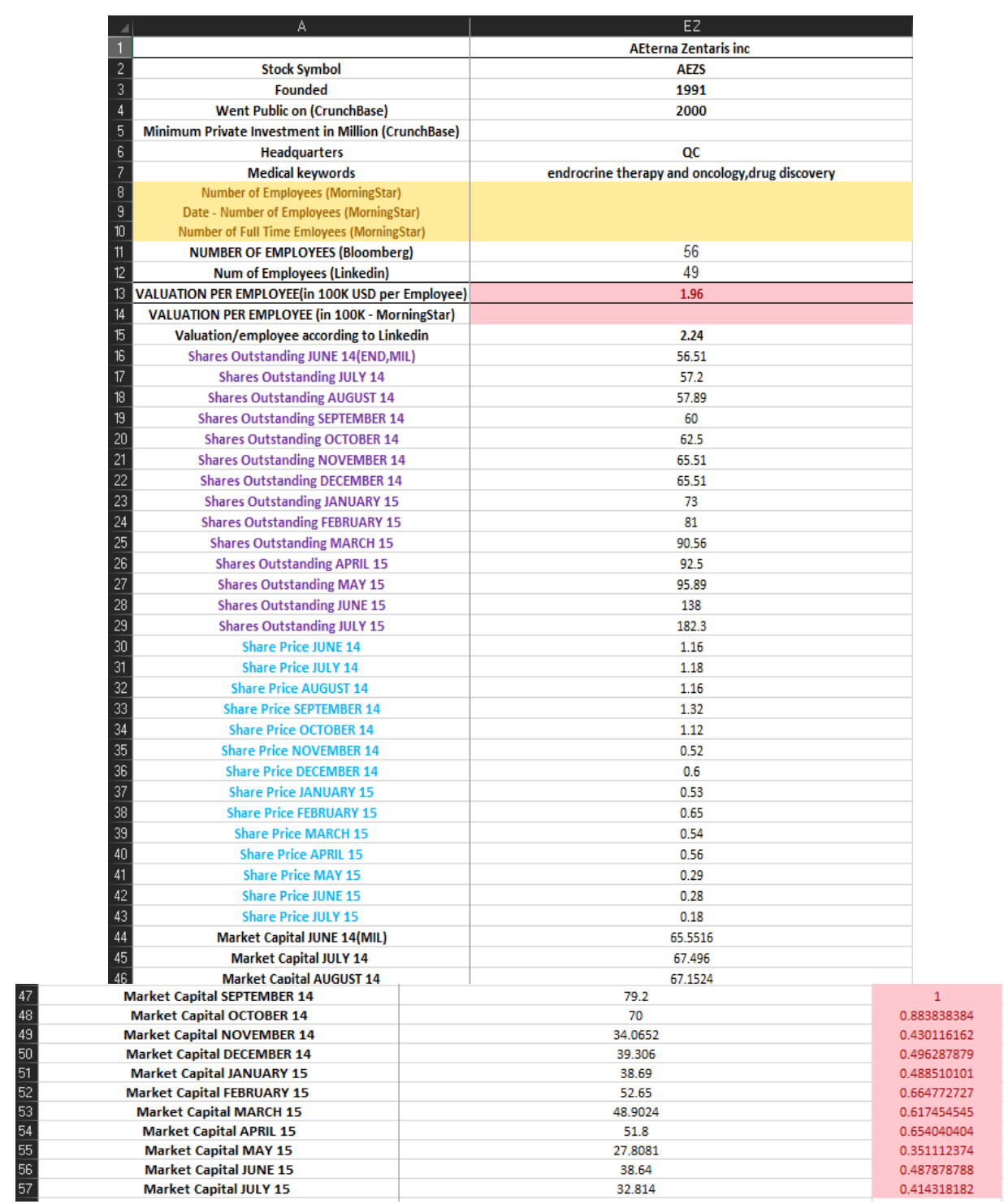

Data points example of Non-Innovative Companies

\section{IV.RESULTS}

After generating the hypothesis, many exciting results were seen. Firstly, the thresholding of these stocks were done and the success rate of profits in investment was very high irrespective of the threshold. As expected, the companies with a very high IP value has an increase in stock price almost always, from the time the IP value was calculated.

The receiver operator analysis shows which threshold would be the best for an inventor for future models and investment plans. According to the receiver operator table given below, the IP threshold of $(175,100)$ is chosen as the best. All companies above an IP value of 175 are considered innovative and all companies below IP values 100 is chosen as non-innovative. This threshold is chosen because of two reasons. Firstly, the percentage of success or the true positive percentage is highest at $85.71 \%$. This means that, if were an investor to invest in a company with an IP value above 175 , there is an $85.71 \%$ chance that he would make profits in the next 3 months. Secondly, if an investor were to invest in a company below IP value of 100 , there is a $50 \%$ chance that he would get profits. This clearly highlights the liquidity of non-innovative companies which intern shows the risk of investment.

Hence an investor must always look to companies which have an IP value of above 175 before investment in order to ensure a higher chance of profit. It is important to note that this is most effective when there has been a recent crash in the markets. The investor must take full advantage of this time period by investing in companies having an IP value of above 175 and avoiding interest in companies with IP values below 100. This peculiar behaviour of innovative companies is studied even more in the next section. 
Vol. 6, Issue 4, April 2017

\begin{tabular}{|c|c|c|c|c|c|c|c|c|c|c|c|c|c|}
\hline \multirow[t]{2}{*}{ CASENUMBER } & \multirow[t]{2}{*}{ 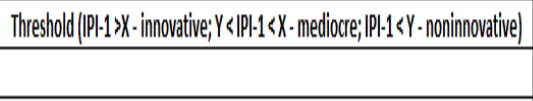 } & \multicolumn{6}{|c|}{ MARKEC CAP } & \multicolumn{6}{|c|}{ SHAREPRICE } \\
\hline & & TP & FP & $T(T P+F P)$ & FN & TN & T(FNTTN) & TP & $\mathrm{FP}$ & $T(T P+F P)$ & FN & PN & T/FNTTN \\
\hline 1 & $|\mathrm{P}| \cdot 1 \cdot 200,50$ & 4 & 1 & 5 & 24 & 15 & 39 & 4 & 1 & 5 & 23 & 16 & 39 \\
\hline 2 & $|P| \cdot 1 \cdot 200,150$ & 4 & 1 & 5 & 34 & 32 & 66 & 4 & 1 & 5 & 35 & 31 & 66 \\
\hline 3 & $|\mathrm{P}| \cdot-1 \cdot 200,100$ & 4 & 1 & 5 & 30 & 30 & 60 & 4 & 1 & 5 & 32 & 28 & 60 \\
\hline 4 & $|\mathrm{P}| \cdot 1 \cdot 200,75$ & 4 & 1 & 5 & 29 & 17 & 46 & 4 & 1 & 5 & 28 & 28 & 46 \\
\hline 5 & $|\mathrm{P}| \mathrm{|} \cdot \mid 175,125$ & 6 & 1 & 7 & 34 & 22 & 56 & 6 & 1 & 7 & 32 & 24 & 56 \\
\hline 6 & $|\mathrm{P}| \mathrm{I} \cdot \mid \cdot 175,100$ & 6 & 1 & 7 & 30 & 30 & 60 & 6 & 1 & 7 & 32 & 28 & 60 \\
\hline 7 & $|P| \cdot \mid \cdot 150,100$ & 9 & 2 & 11 & 30 & 30 & 60 & 9 & 2 & 11 & 32 & 28 & 60 \\
\hline 8 & $|\mathrm{P}| \cdot-1 \cdot 125,75$ & 11 & 3 & 14 & 29 & 17 & 56 & 10 & 4 & 14 & 28 & 28 & 56 \\
\hline 9 & $|P| \cdot 1 \cdot 100,50$ & 14 & 4 & 18 & 24 & 15 & 39 & 13 & 5 & 18 & 23 & 16 & 39 \\
\hline 10 & $|\mathrm{P}| \cdot 1 \cdot 75,25$ & 16 & 8 & 24 & 15 & 8 & 23 & 16 & 8 & 24 & 15 & 8 & 23 \\
\hline
\end{tabular}

\section{CONFIRMATION OF FEASIBILITY OF IP VALUE AS A STOCK MARKET PREDICTION METRIC}

To make the analysis even more firm and to highlight the potential of such a statistical model, its conformation has been represented in the following way.

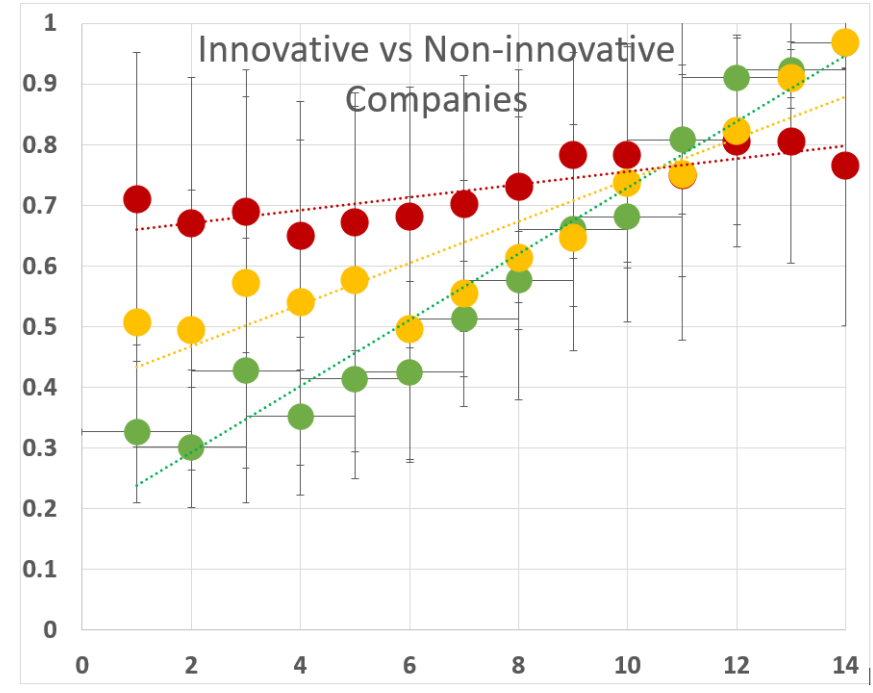

Key of graph

$X$ axis- Months in numeric form (June 2014 to July 2015)

$\mathrm{Y}$ axis- Mean Normalized values of stock price of the three different thresholds against its maximum within the time period of June 2014 to July 2015 (Green represents the predicted innovative companies, red indicates the predicted non-innovative companies and yellow indicate the predicted mediocre companies)

Explanation

In the above plot, the data points of the individual months in the 14-month period are represented as green, red and yellow dots for innovative, non-innovative and mediocre companies respectively. Further, to show the steepness of the curves, straight line curve fitting was done (shown as dotted lines).

It is important to note that these values are normalised against a company's own maximum values of stock price, so the slope of the curve must be looked at and not the y-axis values at each month.

Now, it can be clearly observed that the innovative companies have the steepest graph. This implies that these companies have shot up at the fastest rate in terms of stock price during the recovery of the biotech stocks. The noninnovative companies seem to have an almost flat curve indicating that there was no improvement of the stock price after the crash of the markets. Naturally, the mediocre companies have performed as suspected, a mediocre rise in stock price.

This analysis proves that the proposed big data analytics prediction model proposed for stock markets is indeed applicable. 


\section{VI.MATLAB MODELLING}

For the ease of the investor a MATLAB code was created to increase the automation of the process. This code is disclosed below.

\%step1-read the file

[allnum,lab,eve]=xlsread('Datainput.xlsx');

\%step2-Multiply individual shares outstanding

$\%$ with the share price (multiply row 5 with row 19 , row 6 with row 20 and so on)

so=eve $(6: 19,2:$ end $)$;

$\mathrm{sp}=\mathrm{eve}(21: 34,2$ :end $)$;

marcap $=$ cell2mat(so). *eell2mat(sp);

\% for each company (collumn in eve)

for $\mathrm{i}=2$ :size (eve, 2 )

$\%$ step4-Read date of announcement of number of employees

$\%$ creating two variables anyear and anmonth to represent dates for

\%each company

[anyear(i-1), anmonth(i-1)]=datevec(eve $\{4, \mathrm{i}\}$, 'dd/mm/yy');\%indexin

into (i-1) to have values from first cell in array

$\%$ (prevent writing from second cell)

end

\%step5.1-match andate with SO dates and identify the corresponding SO price

for $\mathrm{i}=1$ :length(anyear)

for $\mathrm{j}=6: 19$

$[\mathrm{y}, \mathrm{m}]=$ datevec $\left(\operatorname{eve}\{\mathrm{j}, 1\},{ }^{\prime} \mathrm{mm} / \mathrm{dd} / \mathrm{yyyy}^{\prime}\right) ;$

if $(\mathrm{y}==\operatorname{anyear}(\mathrm{i})) \& \&(\mathrm{~m}==\operatorname{anmonth}(\mathrm{i}))$

SOprice_andate $(\mathrm{i})=\operatorname{eve}\{\mathrm{j}, \mathrm{i}+1\} ; \% 1+1$ so that companoes start from second collumn

end

end

end

\%step5.2-match andate with SP dates and identify the corresponding SP price

for $\mathrm{i}=1$ :length(anyear)

for $\mathrm{j}=21: 34$

$[\mathrm{y}, \mathrm{m}]=$ datevec $\left(\right.$ eve $\{\mathrm{j}, 1\},{ }^{\prime} \mathrm{mm} / \mathrm{dd} /$ yyyy' $\left.^{\prime}\right)$;

if $(\mathrm{y}==\operatorname{anyear}(\mathrm{i})) \& \&(\mathrm{~m}==\operatorname{anmonth}(\mathrm{i}))$

SPprice_andate $(\mathrm{i})=\operatorname{eve}\{\mathrm{j}, \mathrm{i}+1\} ; \% 1+1$ so that companoes start from second collumn

end

end

end

\%step5.3 multiply SO and SP identified above and divide by No of employees

$\%$ to get IP

for $\mathrm{i}=2$ :size $($ eve, 2$)$

anIP(i-1)=SOprice_andate(i-1)*SPprice_andate(i-1)*10/eve $\{3, \mathrm{i}\} ; \% * 10$ as it is calculated in 100k

end

\%Step6 write IP values back to file

filename $=$ 'Datainput.xlsx';

sheet $=1$;

xlRange $=$ 'B40';

xlswrite(filename,anIP,sheet,xlRange); 


\section{CONCLUSION}

With this statistical model, one can confidently invest in the companies in the Biotechnology sector just after a fall in the global market and expect profits in the next three months, as the companies try to get out of a recent economic meltdown. A $85.71 \%$ success rate for profits has been shown in this illustrative example after the companies. Biotechnology stocks have a great potential in growth and the US have invested heavily in this sector. This sector has shown a lot of promise in recent years and will continue to help investors to make their share of profits. The model proposed will help these investors and hedge funds. This will also help as a component in further in-depth research in this subject

\section{REFERENCES}

[1] http://www.bloomberg.com/research/sectorandindustry/industries/industrydetail.asp?code=352010\&firstrow=20

[2] http://finance.yahoo.com/;_ylt=AhKpu4y5NXAD3xbq0dUbaH5.FJF4

[3] https://ycharts.com/

[4] http://www.gurufocus.com/

[5] http://www.morningstar.com/

[6] https://www.macroaxis.com/

[7] http://in.mathworks.com/index.html?s_tid=gn_logo

[8] https://www.crunchbase.com/

[9] https://in.linkedin.com/

\section{BIOGRAPHY}

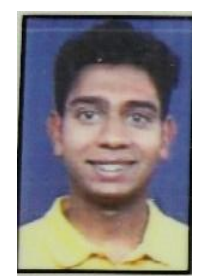

Vishal Kannan who hails from Bangalore (Karnataka) is pursing B.E in Mechanical Engineering at RV College of Engineering, Bangalore. His area of interest includes mechatronics, design, thermodynamics and physics. Other interests include finance, investment and emerging technologies. He was selected for and has successfully completed, a general management program for young leaders at Stanford University. 